\title{
Astronaut Earth Observations During the Space Radar Laboratory Missions
}

\author{
Thomas D. Jones \\ Mail Code CB -- Astronaut Office \\ NASA Johnson Space Center \\ Houston, TX, 77058 \\ 713-244-8978 \\ tdjones@cal.jsc.nasa.gov \\ Linda M. Godwin \\ Mail Code CB -- Astronaut Office \\ NASA JSC, Houston, TX, 77058 \\ 713-244-8802 \\ lgodwin@ca1.jsc.nasa.gov \\ Peter J.Wisoff \\ Mail Code CB -- Astronaut Office \\ NASA JSC, Houston, TX, 77058 \\ 713-244-8708 \\ pwisoff@ca1.jsc.nasa.gov \\ Cindy A. Evans \\ Lockheed-Martin Engineering and Sciences \\ Mail Code SN5 -- Earth Sciences Branch \\ NASA Johnson Space Center \\ Houston, TX 77058 \\ 713-483-0519 \\ evans@sn.jsc.nasa.gov \\ David L. Amsbury \\ Mail Code SN5 -- Earth Sciences Branch \\ NASA Johnson Space Center \\ Houston, TX 77058 \\ $713-483-5160$ \\ damsbury@sn.jsc.nasa.gov
}

\begin{abstract}
Astronaut science operations and observations aboard space shuttle Endeavour were an integral part of two 1994 Space Radar Laboratory (SRL) missions. The crews performed three major functions in support of the radar and atmospheric pollution experiments: (a) maneuvering and pointing Endeavour to cover the hundreds of planned
\end{abstract}

science targets; (b) managing the flood of science data produced by the radars, generated too rapidly for immediate downlink to Earth; and (c) documenting through visible and infrared photography the environmental state of each science site, capturing "ground truth" for comparison with the other mission data sets. Earth photography was planned 
specifically to enhance science return from SRL's instruments: an advanced imaging radar (SIR-C/X-SAR) and a tropospheric carbon monoxide sensor (MAPS). The astronauts went beyond the maintenance of Endeavour as a science platform to play an active role in experiment operations and science activities during Radar Laboratory operations.

By far the most intense and rewarding of these activities was the crew science photography. This imagery constitutes a unique data set on the global environmental state during two seasonal extremes, April and October 1994. The crew captured over 20,000 images of Earth, complementing the unpredecented perspectives on geology, hydrology, oceanography, ecology, and the global carbon cycle gained from SRL radar imagery and pollution measurements.

Real-time crew observations and the extensive photography continue to aid interpretation of the SRL SAR imagery. The photos documented surface environmental conditions over hundreds of science targets where ground truth was absent, linking them to heavily studied science "supersites." MAPS photography focused on carbon monoxide (CO) sources like fires, smoke, and industrial activity; weather conditions at ground $\mathrm{CO}$ sampling sites; and weather systems involved in CO's vertical and lateral transport. Examples of these combined studies of SRL radar and photographic data include: visible and radar imagery over the full course of the violent eruption of the Kamchatkan volcano Kluichevskoi; optical and radar detection of density waves in off-shore currents; discovery of a 13-km-wide impact structure in Korea; mapping and glacier flow measurements of the previously unstudied Patagonian icefields in extreme southern Chile and Argentina; and mapping of lahar movements on the flanks of the Philippine volcano Pinatubo. These photographs, digitally available on the Internet (http://images.jsc.nasa.gov/html/ earth.htm), document deforestation, snow and sea-ice cover, glacier extent, ocean current and wave phenomena, volcanoes, and a host of geologic landforms between $+/-57^{\circ}$ latitude. We present a sampling of images from the data set; they demonstrate the utility and responsiveness of current shuttle photography to global change investigators, and show the potential return from optical systems planned for the International Space Station .

Table of Contents

1. INTRODUCTION

2. ASTRONAUT OPERATIONS ON THE SRL MISSIONS

3. PHOTOGRAPHY FROM ORBIT

4. FUTURE OPPORTUNITIES -- THE EXAMPLE OF SRL

\section{INTRODUCTION}

On September 30,1994, astronauts aboard the Space Shuttle Endeavour (mission STS-68) soared over central Kamchatka and were startled to see a huge, dark gray plume streaming eastward over the Pacific. On subsequent orbits, the crew was able to photograph a spectacular eruption of Klyuchevskaya volcano and downlink video of the event in near real time. Over the course of the mission, the astronauts regularly monitored the waning eruption, recording dark ash flows on the white flanks of the mountain, smaller ash plumes from secondary explosions, and the eventual cloaking of the now-quiet volcano in a fresh mantle of snow. Ten days after the onset of eruption, 
Klyuchevskaya's glistening slopes showed few indications of the recent violence.

The photographic images of the $10-\mathrm{km}$-high eruption plume and subsequent changes on the volcano were doubly valuable, because they were taken in conjunction with multifrequency synthetic aperture radar (SAR) imaging, the major product of Endeavour's Space Radar Laboratory 2 (SRL-2) payload. While nature provided this timely and spectacular example of geologic change, the astronaut observers on Endeavour were wellequipped to take advantage of this opportunity. Crew observations and photography were integral elements of the two Space Radar Lab flights -- the breadth and depth of SRL crew observations demonstrated the utility and responsiveness of humans working in conjunction with remotelyoperated sensors. The astronauts' photography provided both correlative data for the radar, and stand-alone scientific data important for global change research. In the former case, the visible images recorded data (the eruption plume and snow cover) crucial to interpreting the radar images. In the latter, the photographs provided a unique perspective on a large eruption column which would have been otherwise unavailable to geoscientists. The series of photographs of the Klyuchevskaya eruption was seen and used by a diverse audience, from syndicated networks reporting world events to the Federal Aviation Administration (the ash plume disrupted air traffic over heavily traveled North Pacific air routes for a number of days).

The Klyuchevskaya photos are an example of the results obtained from a three-week-long Earth observations campaign mounted during the two 1994 SRL missions. In this paper, we describe how the SRL astronaut crews trained to become integral members of the SRL science team, place the crew observations in the context of the larger plan for SRL experiment operations, and cite the success of these two flights as rationale for an active Earth observation program aboard the International Space Station (ISS).

\section{Earth Observations from Piloted Space Missions}

The SRL astronaut photography, some 25,000 frames, joins a larger data set of astronaut imagery documenting the changing state of Earth's surface. Scientific research on terrestrial features and processes using observations and photographs from space has always been an integral part of the United States piloted spacecraft program $[1,2]$. NASA has sponsored investigations in geography, geology, oceanography, meteorology, and ecology since the Mercury Program of 1961-63. Investigations based on astronaut observations and photographs continued through the Gemini Program of 1965-66, Earth-orbiting Apollo Missions in 1968-69, and reached a pre-shuttle peak with the Skylab space station missions in 1973-74.

The Skylab 4 crew received training on Earth observations from a dozen or so Earth scientists, and conducted a very successful campaign of observations during the 3-month mission. Interactions among investigators and astronauts led to some surprises: desertification in the Africa's Sahel, initially blamed on sand accumulation or encroachment, was linked through field observations and space clata analysis to widespread destructive land use activities in the presence of drought [3]. Specifically, field work and study of Landsat data had not provided insight into the extensive and persistent dust palls and fires throughout the Sahel, nor of similarities in land-use patterns between widely-separated regions, both of 
which were evident to observers in orbit. This fresh insight, achieved from an orbital vantage point, led to specific controls against overgrazing by inhabitants using nomadic herding practices [3]. Raising livestock in fenced compounds limits the impact of grazing on marginal grasslands and soils.

The space shuttle has flown an average of seven times a year since 1988, furnishing a periodic look at the state of Earth's surface. Crew observations and hand-held photographs from these 5- to 16-day missions have provided data for a variety of scientific investigations in ecology and other sciences [4,5]. For example, crew members have documented differential reflectance from sea, land, and cloud surfaces using polarized light [6]; seasonal burning in tropical areas and elsewhere [7]; and an oceanic shear zone in the equatorial Pacific [8]. The average shuttle mission returns some 3,000-5,000 photos of Earth, but those activities are nearly always done on a non-interference basis with other mission objectives, such as rendezvous, EVA, or microgravity research in the shuttle middeck or Spacelab module. Planning for crew observations on the two 1994 SRL was a radical departure from this "as time permits" approach.

The Space Radar Laboratory missions, from launch to landing, were dedicated to studies of Earth's environment. SRL consists of an advanced, multi-frequency synthetic aperture radar, and an infrared gas-filter radiometer that measures the column abundance of carbon monoxide (CO). The U.S. portion of the radar is a phased array SAR that operates at $\mathrm{C}$ and $L$ band, called Shuttle Imaging Radar - C (SIR-C). The German-Italian component is a mechanically tilted slotted waveguide antenna known as X-Band Synthetic Aperture Radar (X-SAR). SIR-C/X-SAR operate together to address problems across the breadth of the
Earth sciences: experiments were planned in geology, oceanography, ecology, hydrology, and electro-magnetic theory $[9,10]$. The $\mathrm{CO}$ pollution sensor, called Measurement of Air Pollution from Satellites (MAPS), would create a global map of combustion sources, and trace the weather systems that distribute pollutants through the troposphere [11]. Both SIR-C/X-SAR and MAPS, working together as the Space Radar Laboratory, would weave space-based measurements together with ground truth from dozens of heavily instrumented "supersites" around the globe that furnished ground truth for the radar and pollution experiments. From the start, the mission concept included the astronaut crews as integrated members of this far-flung science team.

\section{Early Planning for SRL Crew Science Operations}

The SIR-B radar experiment flew on the STS$41 \mathrm{G}$ mission in October 1984. The crew's hand-held photographs aided interpretation of the radar imagery, and the next shuttle radar flight, SIR-C, planned to expand the scope of this complementarity. After SIR-B, Jet Propulsion Laboratory (JPL) and Langley Research Center (LaRC) investigators, and the Johnson Space Center (JSC) science support staff recognized that crew members should be an integral part of the SRL science team. In 1985 plans were well along to add one or two working scientists to each crew as Payload Specialists. The Challenger accident in January 1986 caused a revision in NASA's crew policy. Payload specialists are flown now only if their expertise is required to operate specific payloads or equipment. The SRL experiments, SIR-C/X-SAR and MAPS, were designed for remote operation from the ground, and their payload bay siting precluded any major orbital repairs. The SRL crew, 
then, would come from the career astronaut corps, and their primary science role shifted from detailed payload operation to a monitoring function, freeing them to focus on the enhancement of the radar and MAPS return through gathering of a parallel set of Earth observations.

\section{Crew Training}

Most space shuttle crews do not have the luxury of training for extensive Earth observations. Time is a precious resource in human spaceflight, and the demands of flight operations (e.g. rendezvous, satellite deployment and retrieval, extravehicular activity, and intensive laboratory science) leave little time for systematic observations and photography. Most shuttle crews receive just 20 to 30 hours of Earth science and observation training, and it is the first activity dropped from a tight training schedule or from a flight plan running behind schedule. The SRL crews and their instructors had to design a training program and operations concept equal to the major science role envisioned for the crew.

Because of the scientific complexity of the mission, the JSC Astronaut Office appointed a mission specialist, Dr. Linda Godwin, as Payload Commander some 22 months before the planned September 1993 launch date. She stepped immediately into training in Earth science and the specific experiment goals and physical environments of the various supersites. As the rest of the crew was assigned, they joined her in intensive planning for orbit operations, and site-specific training of steadily increasing complexity.

Both the SRL-1 and -2 crews trained intensively to recognize the specific primary and backup science supersites, as well as environmental phenomena and Earth processes visible from low Earth orbit. The JSC contributed formal Earth observation training, focusing on a geographic framework for the science sites, and identifying visual acquisition cues for all of the radar and MAPS sites. The crew gained familiarity with the SRL sites by map study and extensive review of photography from previous shuttle missions. This classroom study (equivalent to a full graduate-level semester of Earth science and geography) was supplemented by a training manual contributed by student researchers [12], and field visits to several supersites, where the crews worked directly with principal investigators (PIs) across the spectrum of the Earth sciences. On visits to supersites in North America, Australia and Europe, the astronauts gained an impression of each site's terrain and vegetation. More importantly, the crew learned the specifics of the problems addressed by many of the SIRC/X-SAR and MAPS experiments. In turn, the PIs gained insight into the types of orbital observations which could be expected from the crew during data takes.

\section{ASTRONAUT OPERATIONS ON THE SRL MISSIONS}

The crew, working with the SRL scientists and engineers, broke orbit operations into three distinct functions: accurate radar pointing, management of the flood of digital radar data, and SRL science photography.

Two kinds of pointing were necessary for the 50 hours of radar imaging planned for SRL-1. While SIR-C/X-SAR could vary its radar look angle from $20^{\circ}$ to $60^{\circ}$, the antennae were fixed in the cargo bay so that Earth imaging could be done only over Endeavour's starboard side. Thus switching the radar view from one side of the orbital track to the other required a 
$180^{\circ}$ nose-to-tail swap (or vice versa). The second type of pointing maneuver was Zero Doppler Steering (ZDS), conceived and implemented by the JPL science and JSC flight control teams. ZDS is a very slow rotation of the shuttle in azimuth along track, at a rate of $0.003 \% \mathrm{sec}$, designed to reduce the magnitude of the Doppler error introduced into the radar echo by Earth's rotation. The crew performed two ZDS maneuvers, each lasting about 40 minutes, on each 90 -minute orbit. The noseto-tail and ZDS maneuvers combined to give STS-59 407 orbital maneuvers, a record for a shuttle flight. Both kinds of maneuvers required the crew to input the pointing information into Endeavour's computers by keystroke.

During data takes, SIR-C/X-SAR generated digital imagery at the rate of $225 \mathrm{Mb} / \mathrm{sec}$, far exceeding Endeavour's $50 \mathrm{Mb} / \mathrm{sec}$ downlink capacity. To cope with this flood of data, the crew tended a trio of high-speed Schlumberger data recorders, each capable of storing data on tape cassettes at $180 \mathrm{Mb} / \mathrm{sec}$. The tape cassettes could hold up to 50 Gbyte (or 35,000 floppy disks), but SIR-C data would fill one in just 30 minutes. The astronauts fed the seemingly insatiable recorders a constant stream of cassettes, each slightly larger than the familiar VHS video cassette. STS-59 returned 163 data tapes, while STS-68 filled 199 (SRL-2 returned 89 $\mathrm{Tb}$ of data.). Maneuvers and tape changes combined to keep the crew constantly watching the clock, entering maneuver data into the guidance and navigation computers, and slipping tape changes into the brief intervals between radar data takes.

\section{SRL Science Photography}

While the maneuver and recorder management tasks were essential, they were mundane tasks that used the astronaut crew to reduce the complexity and cost of these testbed SRL flights. The third, and by far the most intense activity (though the most rewarding to the crew) was the SRL science photography [13]. The purpose of the photography was to provide, through color and infrared imagery, a comparison data set to augment interpretation of the radar imagery. The photographs, covering the same ground swath as SIR-C/XSAR, would document the environmental state at the supersites, eliminate ambiguities caused by storms, clouds, or snow cover, and serve as "ground truth" over sites where no field teams were deployed for surface measurements.

Fourteen different cameras were available onboard Endeavour for SRL support: 4 payload bay cameras, 2 Linhof 'mapping cameras, 4 Hasselblad handheld cameras, 2 Nikon $35 \mathrm{~mm}$ cameras, and 2 Sony camcorders. The primary Earth observation cameras were the NASA-modified Hasselblad $500 \mathrm{EL} / \mathrm{M}$, using $70 \mathrm{~mm}$ film, and the Linhof Aero Technika 45 , using a $12.5 \mathrm{~cm}$ film format [14]. The Linhof mapping camera was mounted in Endeavour's starboard overhead window; the crew manually tilted the camera through a range of 35 degrees to match the boresight of the radar look angle. The Hasselblads used an array of lenses from 40 to $250 \mathrm{~mm}$ in focal length. Both the Linhof and Hasselblads used color positive film (Kodak Lumiere 100 and Ektachrome 5036), while one Hasselblad body used color infrared (Kodak Aerochrome 2443). Each mission carried a film inventory sufficient to map each SRL supersite and MAPS ground calibration site at least once, with the Linhof obtaining a strip map to correspond with the radar swath, and the Hasselblads providing a variety of oblique and synoptic views of the 
environmental conditions during each daytime radar data take.

The Hasselblad with the Zeiss $100 \mathrm{~mm}$ lens provided $80 \mathrm{~m}$ spatial resolution, similar to that of the Landsat Multi-spectral Scanner. The $250 \mathrm{~mm}$ Zeiss/Hasselblad combination provided $30 \mathrm{~m}$ resolution, akin to the Landsat Thematic Mapper; this was close to SIR-C/XSAR's $20 \mathrm{~m}$ resolution, but with a larger field of view. The Linhof mapping system with a $250 \mathrm{~mm}$ lens matched the Hasselblad resolution at $20 \mathrm{~m}$, but had the advantage of overlapping the SAR swath with a continuous strip that placed the radar images in a regional context.

To supplement the limited still photo film inventory, the crews used the remotely operated payload bay video cameras to image every daytime radar data take. The crew aimed the payload bay camera parallel to the SIR-C/X-SAR look angle, and recorded video of the target swath, along with audio from the aft flight deck. The video cassettes thus contain a complete record of weather and environmental conditions along the radar swath, and the verbal science observations of the crew regarding snow and ice cover, thunderstorms, sea ice, local fires and smoke, blowing dust, etc. at each site. These recordings could be played back to ground investigators during the mission for near-realtime interpretation alongside samples of the radar imagery, enabling replanning for transient events like the Klyuchevskaya eruption during SRL-2.

\section{Photography Operations Concept}

Orbit operations ran around the clock on SRL-1 and -2. The six crewmembers were split into two three-person shifts, each covering 12 hours of science operations. Each of these shifts covered about 16 orbits (SRL-1 and -2 each flew 183 orbits, each revolution taking approximately 89 minutes.). First priority during each "rev" was accorded to orbiter maneuvers, followed by the crucial data cassette changes. For each data take, the crew monitored displays of radar operating modes and payload high rate recorder (PHRR) status. Once the data take was underway and radar and PHRRs were operating nominally, the crew made verbal observations of the science targets, recording them on the video system or relaying them in real-time via radio to the Payload Operations Control Center (POCC) at JSC. During the 44-minute daylight portion of each orbit, assuming the SLR hardware was operating properly, the crew engaged in intensive photography over each radar target.

At a speed of $5 \mathrm{~km} / \mathrm{sec}$ and an altitude of 220 $\mathrm{km}$, visually acquiring each of the more than 400 science targets was a significant challenge. Beyond the preflight training in site recognition, the astronauts and ground teams developed a suite of tools to keep the crew geographically oriented. Maps were the core of the tool kit: the challenge was to carry maps sufficiently detailed to be useful without wall-papering Endeavour's cockpit. Anyone who has wrestled with unfolding a map in an automobile at highway speeds can appreciate the difficulties in working with a weightless map or atlas while traveling at $28,200 \mathrm{~km} / \mathrm{h}$. The crew used a medium-scale atlas, plotted with mission ground tracks and SRL science sites, organized by orbit number. This format enabled the proper ground track to be found in a matter of seconds. The science team provided the "big picture" by uplinking a global map of the data takes and ground tracks for each flight day, using the orbiter's Thermal Impact Printer System, essentially a fax machine. 
We augmented the maps with a JSCdeveloped computerized world map. A 486based IBM Thinkpad $755 \mathrm{C}$ ran a real-time display showing Endeavour's current position over a shaded relief atlas presentation, which included the science site locations. The crew could instantly pull up the name of each science site, country, city, or physical feature depicted. The software map kept us oriented sufficiently well to move quickly to the proper section of the atlas pages.

With hundreds of data takes planned over the 10 days on-orbit, the crew needed a system to track photography of the science sites and record highlights of each observation. $L$. Godwin developed a software tool for logging the camera/lens combinations and film magazines used during each data take. The crews also used her software to record notes about each pass and the environmental state of the target. A major advantage of this tool was that the crew could downlink the recorded data to the POCC daily, using Endeavour's portable audio data modem. The POCC science planners could thus flag crew observations and relay them to the field teams, and mark particular film magazines for priority examination upon landing.

\section{PHOTOGRAPHY FROM ORBIT}

The limiting consumable for crew science operations was Endeavour's film budget. While the 12,000-frame budget for Earth photography was more than double the usual shuttle inventory, it was not sufficient to photo-map all of the daylight radar passes. We gave first priority for each data take (usually thousands of $\mathrm{km}$ in length) to the section centered on the science site itself. The plan was to use the boresighted Linhof camera to photograph at least one radar pass over each site, preferably in clear weather. The video tracks from the payload bay cameras augmented the Linhof swath. We then allotted the hand-held Linhof and Hasselblads to obtaining detailed and synoptic views of meteorological and environmental phenomena, sunglint opportunities, and repeat passes over targets, film permitting.

Once in orbit, the science photography fell into a comfortable, if hectic, routine. With orbiter maneuvers safely loaded into Endeavour's computers, and the PHRRs loaded with fresh tapes, the crew used the waning minutes of each orbital night to brief the radar and MAPS targets scheduled for the daylight pass. Maps were studied, cameras and film checked, and the Linhof and payload bay camera aligned with the planned radar look angle. At sunrise, one astronaut manned the Linhof on its boresighted mount, and the other two took station at the flight deck windows pointed closest to nadir. Video and audio recording began with the start of each radar data take, while the team searched for the site visual cues as they appeared over the horizon. The crew strove to acquire each target with the naked eye as far uptrack as possible -- seconds counted, and early sightings meant much more time was available to choose the best lens and exposure settings. With the target in view, the pace approached a controlled frenzy, with verbal f-stop settings and comments on the site competing with the clack of shutters firing and the whine of motor drives pulling fresh film from the magazines. The window-mounted Linhof's vacuum pump purred smoothly in the background, an intervalometer tripping the shutter every ten seconds, providing a $10 \%$ overlap with the previous frame. In free-fall, the three astronauts twisted their bodies into the best 


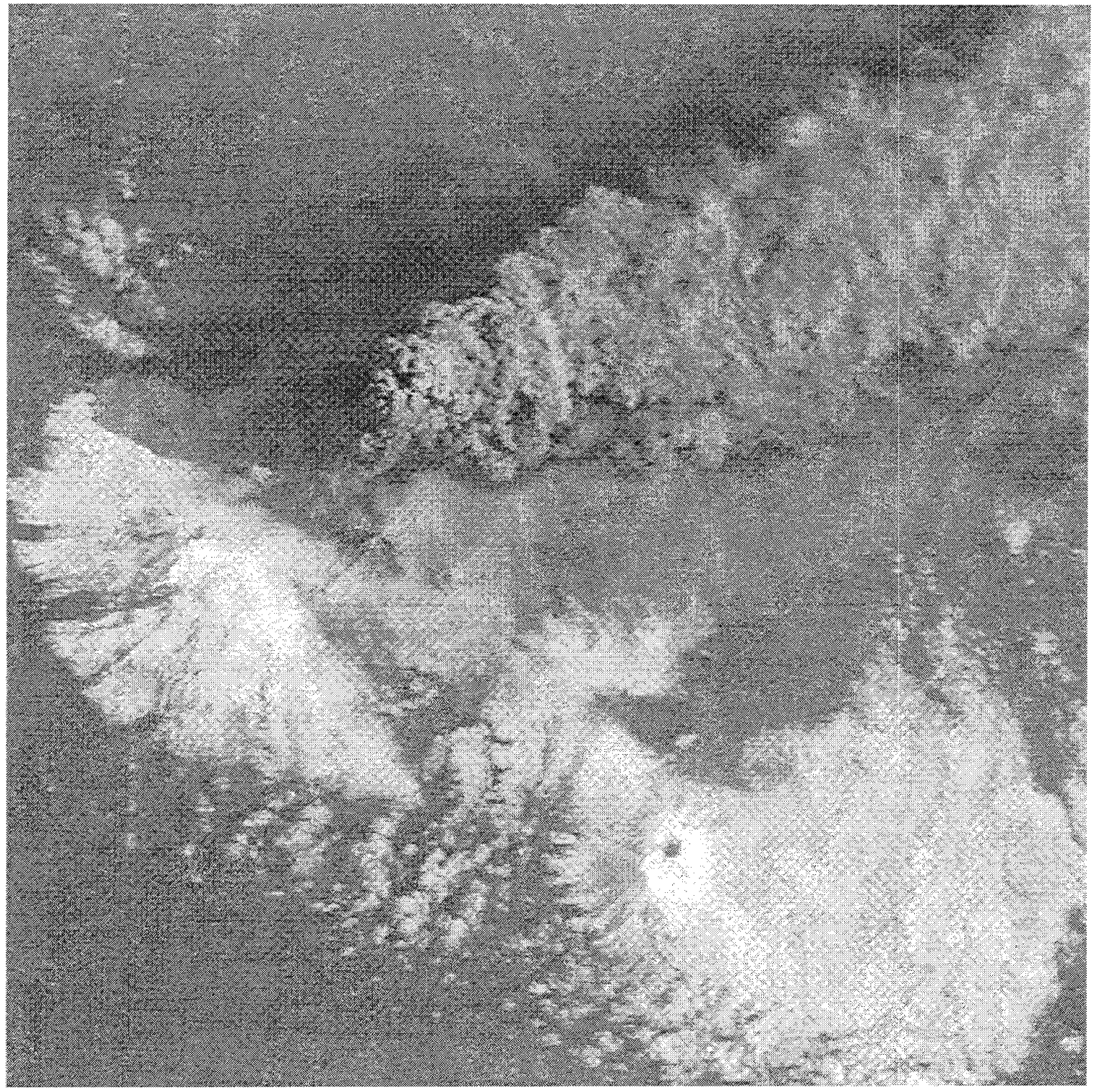

Figure 1. Nadir view of the erupting Klyuchevskaya volcano, Kamchatka, Russia, 1 Oct 1994. The main plume and Bezymyanny's steam plume blow eastward while finer dust coats the range's eastern flanks. Downslope steam explosions are barely visible in the plume shadow as hot lahars roll down Klyuchevskaya's northern flanks. The crew of STS-68 launched on 30 Sep 94, the day this peak, the tallest volcano in Asia, exploded into life. NASA STS068-214-045. 
orientation to capture the desired nadir or oblique perspective. It was not unusual to find crewmembers' bodies floating in three completely orthogonal axes during a mapping pass!

The crew used the interval between data takes (sometimes only a few seconds) to log observations and prepare for the next target. One crew member logged the site observations and photography coverage into the laptop for eventual downlink, another relayed site conditions and highlights to the POCC via radio, and a third aimed the Linhof and payload bay camera for the next data take. This steady flow of observations via voice and computer downlink kept the POCC appraised of the environmental conditions at each site during the data take, of considerable use in interpreting the real-time SAR imagery processed at JPL and in Germany. In turn, the POCC fed weather and target cues (changes to closest approach times, sunglint predictions, etc.) to the crew, along with an updated science timeline every 12 hours. The revised timeline capitalized on the crew's reports of transient phenomena (e.g. storms, volcanic activity, pollution, dust, sea ice, snow) and extracted the best return from the limited film budget. On SRL-2, the crew observations of Klyuchevskaya's explosive on-going eruption led to extensive retargeting of the planned radar data takes over Kamchatka. Astronaut photography blanketed the entire five-day course of the eruption.

Besides the sight of a spectacular volcanic eruption, and the breathtaking scenes of Earth sliding by Endeavour's windows, occasional problems cropped up to keep the daily 12hour shifts from becoming repetitive. On SRL-1, the \#1 PHRR suffered an increasingly degraded playback capability due to a power supply failure. Despite crew efforts to clean the heads and adjust playback tracking, the machine was eventually declared failed; the other two recorders handled the radar output for the remainder of the flight. The only failure in the camera suite was the Linhof $250 \mathrm{~mm}$ lens; its loss actually helped the tight film budget by moving mapping operations onto the $90 \mathrm{~mm}$ wide angle lens, permitting a longer interval between Linhof frame exposures.

SRL-2 lost a vernier steering jet about midway through the flight, curtailing radar observations for about 15 hours while Mission Control developed and uplinked a software fix to restore control of the thruster. The lost observations were made up by extending the flight by a day. On flight day 8 , PHRR \#1 (a different unit than on SRL-1) failed, but this time the crew replaced it with a spare in a little over two hours, with minimal science loss. Just as on the first mission, the SRL-2 crew expended their entire Earth-dedicated film inventory by the last flight day.

The quantity of returned film was staggering by previous shuttle standards. Earth photography on SRL-1 exceeded 12,000 frames; on SRL-2, with a slightly larger film inventory, exposed 14,000 frames, including 12,347 Linhof and Hasselblad shots. Upon landing, each crew spent over a week reviewing the film, scanning the thousands of images for highlights of interest to the SIRC/X-SAR and MAPS teams. The photography proved useful to nearly every discipline involved in the mission.

For example, in oceanography, photos of the radar swath taken in sunglint reveal eddy and current patterns that correlate directly with the radar images. Since smoother surfaces, caused by calm winds or surface slicks, are brighter in sunglint, the visible patterns furnish 
ground truth to verify models of radar interaction with the sea surface.

Focusing on the globe's forest ecosystems, the crew photographed huge fire scars in central and east Asia, a vegetation difference important to radar interpretation. Both radar investigators and MAPS scientists kept careful track of crew calls about fires and smoke visible from orbit, especially during orbital night. The huge smoke pall observed and photographed over the East Indies was fed by fires in the region's beseiged tropical forests, and the photos correlate well with both MAPS $\mathrm{CO}$ peaks and patterns of deforestation observed in radar imagery.

For hydrological studies of watershed snow and ice cover and its equivalent water content, the crew obtained synoptic photos of supersites like Mammoth, CA (in the Sierra Nevada) and the Himalayas. These images verified the snow cover extent independently, and proved the ability of spaceborne radar to make accurate maps of such resources. Crew photography of Patagonian glacier fields in the southern Andes was the only source of independent verification for radar imagery of these remote ice fields, being evaluated as possible early indicators of global warming.

Clouds and rain, while of little concern to radar imagery of the surface, were themselves the focus of experiments. Planners of the tropical rainfall experiment needed active thunderstorms in their field of view; the crew's verbal observations on successive orbits were far more accurate than satellite photos in pinpointing the best areas for data takes. Astronaut plots of night thunderstorm activity over the Amazon also explained anomalous echoes seen in X-SAR imagery of the rain forest: heavy rain in the storms actually shadowed the forest canopy from the $3-\mathrm{cm}$ radar beam, creating dark areas in the image swath. These shadows went unexplained until the POCC correlated them with crew calls of lightning during those same passes.

For the MAPS experimenters, real-time Earth observations were key to validating the spaceborne $\mathrm{CO}$ abundance measurements. We reported to the POCC every fire we could see, from flaring natural gas in oilfields off South America, to creeping wildfires on the African savannahs, to hundreds of forest fires blanketing the East Indies and northern Australia in a pall of gray smoke. The crew photography caputred fires, smoke, pollution, and thunderstorms with a synoptic view unavailable to any narrow-field or groundcontrolled instrument. These images constitute a data set providing planet-wide information on $\mathrm{CO}$ production and its vertical and horizontal transport.

The value of the crew photography was probably most easily seen in the geology experiments. Visible imagery served as a check on radar interpretation of nearly every terrestrial landform. The fifteen U.N. Decade Volcanoes, all potential threats to large populations, were a special target of radar and crew observations. The crew's Klyuchevskaya photographs furnished the best available documentary record of that eruption, correlating radar observations of hot ash and mudflows down the peak's flanks with the active summit vents and secondary pyroclastic explosions farther down slope. At Mt. Pinatubo in the Philippines, the radar effectively tracked the progress of mudflows down the mountain's flanks, but could not observe details within the radar-smooth lahars [15]. The complementary crew photos could clearly pick out details such as standing water within the flows, particularly in sunglint. Temporary perched lakes, held back by natural dams of ash and debris, threaten downslope 
villages and farms. Shuttle photos from 1995 96 should be especially valuable in tracking damaging flows mobilized by super-typhoon Angela in November 1995.

SRL crew photography has led to new discoveries outside the focus of the planned radar and MAPS experiments. Because of our arsenal of cameras and work stations under Endeavour's windows, we were able to capture Earth phenomena that had previously escaped notice. The best example is our discovery of two probable asteroid impact craters in Asia. One is east of Lake Baikal in Russia, the other just a few miles outside Seoul, South Korea [16]. Neither had been noticed in any previous orbital photography or geological survey; their discovery from orbit illustrates the potential of expanding the partnership between humans and robotic observers in studying our planet's surface.

Endeavour's landing at Edwards AFB on 11 Oct 94, ending the SRL-2 mission, capped two superb missions to Planet Earth. SIR$\mathrm{C} / \mathrm{X}-\mathrm{SAR}$ imaged 150 million square kilometers of the Earth's surface, observing about $15 \%$ of the globe. The two missions returned over 205 hours of radar data, which equates to over 100 terabits of imagery data -a collection of pictures that would fill a 45,000-volume encyclopedia. MAPS, gathering 447 hours of data, created a series of global carbon monoxide maps, tracing the path of pollutants through Earth's dynamic atmosphere at opposite ends of the year. By returning the largest complement of Earth photography from any piloted space missions (over 24,000 frames in all), Endeavour's crews produced a record of the state of Earth's surface that will prove valuable in global change research efforts. In the nearterm, the SRL imagery data invite comparison to satellite imagery in other wavelengths (e.g. DMSP and GOES platforms), which should produce synergistic results similar to those from SRL astronaut and radar observations.

\section{FUTURE OPPORTUNITIES -- THE EXAMPLE OF SRL}

Humans significantly augmented the science return from the two SRL missions, and the success of astronauts as science observers and team members on these two flights can serve as a model for future Earth observations on shuttle and aboard the international space station. What advantages do human observers offer over conventional Earth satellite imagery?

The astronauts' photos are unique in several respects from more traditional satellite remote sensing data. Low Earth orbit $(\sim 160-500 \mathrm{~km}$ altitude) provides a vantage point intermediate between aircraft and coverage from many satellites. Astronaut photography adds the human perspective -- the regional context encompassed by the image was framed by a human eye -- and the results frequently succeed in integrating topography, land use, cultural geography, and ongoing physical change into a single multi-dimensional view. Crew members can consciously vary the choice of lens, look direction and lighting to capture Earth phenomena in a way that nadirlooking satelllites cannot. In addition, humans operate in "discovery mode" -- they look for the unusual. They can and do notice dynamic events like volcanic eruptions or dust storms, report smoke distributions, or capture the ocean's sunglint to reveal surface structures. They are drawn to patterns out of the ordinary -- the circular rim of an impact crater in a subdued landscape, the glint of sunlight off floodwaters, the wispy plumes of forest fires. These "targets of opportunity" require a trained observer to capture them for ground researchers. 
One significant enhancement to shuttle Earth observations since SRL-2 is the availability of a digital electronic still camera, using a CCD in a modified Nikon camera body. Shuttle crews can now review a limited number (a few dozen per day) of images onboard, and downlink them daily to ground investigators. An expanded digital capability is envisioned for the international space station.

\section{$S R L-3$}

As of early 1996, plans for the third SRL flight call for a launch in mid-1998 on a mission dedicated to generating a global topography map. Rather than focusing on a few dozen science supersites around the planet, the ground track would cover $80 \%$ of the world's landmass, creating a digital elevation data set with sufficient spatial and vertical resolution to serve as a baseline for the next several decades of global change research. The topography data alone will be of immense value to civil and military users, and the global radar imagery will document the present state of Earth's surface, much as the Magellan imagery furnished a global mosaic of Venus. The SRL-3 astronauts will again have near-global access, coupled with a mission profile favorable for Earth science photography.

\section{Shuttle-Mir}

The Russian space station Mir has been in orbit since 1986 at a $51.6^{\circ}$ inclination, the same planned for the International Space Station [17]. Despite the favorable ground coverage for Earth viewing, Mir has labored under a few disadvantages. Film stocks onboard are limited by the capacities of the Progress and Soyuz transfer vehicles. During long-term storage both before exposure and while awaiting return, film is subject to radiation and temperature degradation. The Mir windows are also not optimal for Earth studies (size and optical quality), and the station lacks the latest onboard tools for predicting and logging observing opportunities. None of this is surprising, given the fact that Earth observations aboard Mir, like those on most shuttle missions, are not a high priority. As the Shuttle/Mir series continues, joint Earth observation opportunities are improving: the visiting U.S. astronaut augments the crew hours available for science photography, U.S. scientists are supplementing Russian crew training, and the shuttle visits shorten film storage and turnaround time.

The long-duration Shuttle-Mir missions planned for 1996 and 1997 include a series of directed photographic campaigns over specified research areas. Crews will document specific terrestrial changes over intervals beyond the short orbital capacity of Shuttle. Included in this program are experiments to collect simultaneous, coupled data -- astronaut photography along with imagery from remotely-operated sensors on Mir's Priroda module. Crew observations will add temporal continuity and regional context to the shorter, concentrated Priroda data takes. The most valuable return from these long-term Mir operations, though, will be the experience gained in planning for Earth observations aboard ISS.

\section{Earth Studies from International Space} Station (ISS)

The SRL missions provided an important demonstration of astronaut involvement in dedicated Earth observations experiments, like those envisioned on a larger scale for ISS, scheduled to be operational by the year 2000 . 
At the same time, early components of the Earth Observing System (EOS) will be launched: Landsat 7 and the EOS AM-1 satellite should both be in orbit by mid-1998. As EOS PM-1, CHEM-1, and the Tropical Rainfall Measuring Mission join the constellation after 2000, opportunities will open for linked observations between EOS sensors and continuing astronaut observations.

We expect that by 2000 , high-resolution (comparable to aerial photography) visiblelight and radar imagery, along with a variety of gas-chemistry data, will be available routinely from commercially viable unmanned satellites $[18,19]$. ISS astronauts will be working in an atmosphere of increasingly active monitoring of the global environment. The U.S. Laboratory Module with an optical quality window will be launched to the ISS in late 1998 , to be joined by the multi-windowed cupola a year later. With the Lab's viewport supplemented by the large windows of the cupola, the ISS crew will be able to perform both film-based and digital imaging of Earth. Plans are underway for integrating a suite of electro-optical and conventional cameras into U.S. Laboratory experiments, and providing interactive tools for the station and ground teams, modeled on the SRL POCC. Limited real-time downlink, as well adequate film storage capacity and shuttle return of exposed film, should expand the productivity of human observers dramatically. (Notwithstanding the well-grounded plans for this ISS capability, budget constraints on funding station-based payloads still threaten these capabilities.) The capacity of ISS observers to recognize, evaluate, and collect timely data on Earth phenomena should not only complement but leverage the value of other Mission To Planet Earth information.

\section{Conclusions}

1. Humans in space can make significant contributions to our understanding of Earth as a global system. The Space Radar Laboratory missions demonstrated the large science return possible when Earth observations planning and training are made a mission goal.

2. Meaningful Earth observations programs for piloted space missions demand input from the science community. NASA must solicit imagery requirements from the Earth sciences and global change research communities, and continually feed those demands into the design of the imaging campaign. Returned imagery must go promptly back to investigators.

3. To be effective as Earth observers, crews require a dedicated training program for Earth observations, equal in depth to other mission science training.

4. Earth observations aboard the International Space Station must be integrated into daily science planning. Successful Earth monitoring aboard ISS depends upon prudent investment in imaging hardware, onboard tools, and an experience-based operations scheme.

The value of the SRL experience in planning for ISS is its clear demonstration of how a well-planned, concerted Earth observation effort addressed complex, first-order research problems in the Earth sciences. Building on this experience must be a priority in our continuing and urgent study of the home planet. 


\section{APPENDIX}

\section{Access to the Photographs}

The astronaut photographs are in the public domain and available without restriction. Images for viewing are available in several formats, and hard copies of individual frames can be ordered for reasonable prices. The greatest challenge is to find appropriate images in a collection of images numbering a quarter million. Several sources have been developed to aid in this search:

1. Data Base - A computerized data base (called the Space Shuttle Earth Observations or SSEOP database) containing more than 15 descriptors for each frame of Earth-looking photography is maintained. It includes selected images digitized for user download on File Transfer Protocol (FTP). A data base query can be made through Internet, DECnet, or direct dial. Current searches are relatively slow, but improvements are underway. To access via Internet, Telnet sseop.jsc.nasa.gov and at the "username" prompt, enter photos. Other access instructions are available from the Earth Science Branch, SN5, Johnson Space Center, Houston TX 77058.

2. World Wide Web - Representative global coverage from the first radar mission SRL-1 (STS-59) and another recent high latitude mission can be accessed through http://ersaf.jsc.nasa.gov/sn5.html. Specific photogrpahs from both images which pair well with processed radar data can be accessed through JPL's radar home page, http://southport.jpl.nasa.gov. Finally, a selection of the outstanding photographs from each US space mission is available at http://images.jsc.nasa.gov. Choose "Press Release" for selected images with captions. Choose "Earth Observations" for the entire set of photographs from several recent shuttle missions. Images can be viewed with appropriate software (eg. JPEG) and downloaded..

3. Catalogs - A catalog of information about the photographs from each Space Shuttle mission can be obtained by contacting the Earth Data Analysis Center (EDAC) at the address below.

4. Videodises - Over 150,000 astronaut photographs of Earth are currently available on two 12-inch laser videodiscs, although no photography from the radar missions is included. Both discs are accompanied by a guide describing each mission and computer discs which allow searching for specific images. Photographs from the first 44 Shuttle missions are available on Disc 1 through the Education \& Information Services Branch, Mail Code AP2, at the Johnson Space Center. Disc 2, covering the next 13 missions and showing crews at work on Apollo and earlier programs is now available from NASA's Central Operation of Resources for Educators (CORE). Disc 1 costs $\$ 55.00$ and Disc 2 costs $\$ 61.00$.

\section{Ordering Photographs}

Prints, slides, and transparencies of Space Shuttle Earth-looking photographs are distributed at nominal cost through these agencies:

Earth Data Analysis Center (EDAC)

University of New Mexico

Albuquerque, NM 87131-6031

Phone: (505) 277-3622 Fax: (505) 277-3614

Media Services Branch

Still Photography Library

NASA/Johnson Space Center

P.O. Box 58425, Mail Code AP3 
Houston, TX 77258-8425

Phone: (713) 483-8604 Fax: (713) 483-4876

\section{ACKNOWLEDGEMENTS}

Thanks of the first order go to the crews of STS-59 and STS-68, the first two SRL missions. These spacefaring colleagues did nothing less than risk all to obtain an unprecedented body of knowledge about planet Earth.

\section{STS-59}

$\begin{array}{ll}\text { Commander } & \text { Sid Gutierrez } \\ \text { Pilot } & \text { Kevin Chilton } \\ \text { Mission Specialist 1 } & \text { Jay Apt } \\ \text { Mission Specialist 2 } & \text { Rich Clifford } \\ \text { Mission Specialist 3 } & \begin{array}{l}\text { Linda M. Godwin } \\ \text { (Payload Commander) }\end{array} \\ \text { Mission Specialist 4 } & \text { Tom Jones }\end{array}$

\section{STS-68}

$\begin{array}{ll}\text { Commander } & \text { Mike Baker } \\ \text { Pilot } & \text { Terry Wilcutt } \\ \text { Mission Specialist 1 } & \text { Steve Smith } \\ \text { Mission Specialist 2 } & \text { Dan Bursch } \\ \text { Mission Specialist 3 } & \text { Jeff Wisoff } \\ \text { Mission Specialist 4 } & \begin{array}{l}\text { Tom Jones } \\ \text { (Payload Commander) }\end{array}\end{array}$

We also recognize the superb accomplishments of the Space Radar Lab team, whose scientific and engineering skills brought singular success to these two Missions to Planet Earth. Particular thanks go to Jo Bea Way, Diane Evans, Ellen Stofan, Steve Wall, Mike Kobrick, and Ben Holt at JPL, Hank Reichle and Vickie Connors at Langley, and Justin Wilkinson at JSC. Their efforts were instrumental in making the astronauts integral members of the SRL science team. Finally, we cannot forget the contributions of the hundreds of dedicated people at JSC and KSC, and at the German and Italian space agencies, who devote their talents to making each human foray into space a meaningful success. Space Radar Lab was one of their finest efforts.

\section{REFERENCES}

[1] P.D. Lowman, Jr., "Geology from space: A brief history of orbital remote sensing," in Geologists and Ideas: A history of North American geology. (E.T. Drake and W.M. Jordan, Eds.), Geological Society of America, Centennial Special Volume 1, p. 481-519, 1985.

[2] D.L. Amsbury, "United States manned observations of Earth before the

Space Shuttle," Geocarto International 4, no. 1, 7. 14, 1989.

[3] N.H. MacLeod, J.S. Schubert, and Anaejionu, "Report on the Skylab 4 African drought and arid lands experiment" in Skylab Explores the Earth, NASA SP-380, Lyndon B. Johnson Space Center, 263286, 1977.

[4] M.R. Helfert and K.P. Lulla, Eds. "Humandirected Earth observations from space," Geocarto International, 4, no. 1, 80 p., 1989.

[5] K.P. Lulla, M.R. Helfert, C. Evans, M.J. Wilkinson, D. Pitts, and D.L. Amsbury, "Global geological applications of the Space Shuttle Earth Observations Photography Database," Photogrammetric Engineering and Remote Sensing, LIX, no. 8, 1225-1231, 1993.

[6] V.S. Whitehead and K.L. Coulson, "Earth scenes in polarized light observed from the Space Shuttle" Geocarto International, 4, no. 1, 31-37, 1989.

[7] M.R. Helfert and K.P. Lulla, "Mapping continental-scale biomass burning and smoke palls over the Amazon Basin as observed from the Space Shuttle," Photogrammetric Engineering and Remote Sensing, 56, no. 10, 1367-1373, 1990.

[8] J.A. Yoder, S.G. Ackelson, R.T. Barber, P. Flament, and R.T. Balch, 
"A line in the sea," Nature 371, no. 6499, 689-692, 1994.

[9] D.L. Evans, C. Elachi, E. R. Stofan, B. Holt, J. B. Way, M. Kobrick, H. Ottl, P. Pampaloni, M. Vogt, S. Wall, J. vanZyl and M. Schier, "The Shuttle Imaging Radar-C and X-SAR Mission," Eos Transactions, 74, 145-158, 1993.

[10] C.L. Hughes and R.O. Hill, Mission Evaluation Report: Space Radar Laboratory Missions, JSC26908, NASA Lyndon B. Johnson Space Center: Mission Management Office, Science Payloads Management Office, 1995.

[11] V. Connors, M. Flood, T. Jones, B. Gormsen, S. Nolf, and H.G. Reichle, Jr. "Global Distribution of Biomass Burning and Carbon Monoxide in the Middle Troposphere During Early April and October 1994," in Proceedings of the Chapman Conference on Biomass Burning and Global Change. March 13-17, 1995. Williamsburg, Virginia: July 1995, in press.

[12] J.B. Way and B. Holt, Earth observations by the astronauts in support of the Shuttle Imaging Radar (SIR-C/X-SAR). Pasadena: Jet Propulsion Laboratory, California Institute of Technology, 1993.

[13] J.B. Way, B. Holt, M. Kobrick, T.D. Jones, L.M. Godwin, S.M. Gutierrez, K. Chilton, J. Apt, M.R.U. Clifford, M. Baker, T. Wilcutt, P.J. Wisoff, D. Bursch, S. Smith, C. Evans, V. Connors, A. Campbell, and J. Woodring, "Use of crew Earth observations in the interpretation of imaging radar and carbon monoxide data from the Space Radar Laboratory," Submitted to Earth Interactions, 1996.

[14] D.L. Amsbury and J. Bremer, "Medium format cameras used by NASA astronauts," Geocarto International, 4, no. 3, 59-62, 1989.

[15] C. A. Evans and J. Umbal, "Mapping of Pinatubo lahars over the 1994 monsoon season using Shuttle Imaging Radar-C (SIR-C) and Space Shuttle photographs," Abstracts with Program, Geological Society of America 1994 annual meeting, 26, no. 7, ISSN 0016-7592, 128, 1994.

[16] T.D. Jones, E. Fleming, A. Hatheway, W. McIntosh, and C.J. Shellum, "The Seoul Impact Structure -- Discovery And Assessment," submitted to Meteoritics and Planetary Science, 1996.
[17] A. Koval and L. Desinov, Space flights serve life on Earth, Moscow: Progress Publishers, 286 p. (in English), 1987.

[18] G. Asrar and R. Greenstone, 1995 MTPE/EOS Reference Handbook, NP-215, Greenbelt, MD: NASA Goddard Spaceflight Center, 277 p., 1995.

[19] B. Tripp, "Earlybird Satellite expected to sharpen focus of commercial remote sensing industry," Earth Observation, 4, no. 10, 46-48, 1995.

Thomas $D$. Jones has been a mission specialist astronaut at NASA's Johnson Space Center since 1990. He flew on two Space Radar Laboratory missions aboard shuttle Endeavour in 1994, and is a crew member on the STS-80 shuttle mission scheduled for fall 1996. A former Air Force officer and pilot, he commanded a B-52D Stratofortress combat crew during the early 1980s. A planetary scientist, he has conducted telescopic searches for water on the surfaces of primitive asteroids, and is interested in terrestrial impact structures, remote sensing of the planets, and human exploration of asteroids, the Moon, and Mars. He has a B.S. in Basic Sciences from the United States Air Force Academy, and a Ph.D. in Planetary Science from the University of Arizona.

Linda M. Godwin has been a mission specialist astronaut at the Johnson Space Center since 1985. She joined NASA in 1980, serving as a flight controller and payloads officer in Mission Control for several shuttle missions. She flew on STS-37 in April 1991, deploying the Gamma Ray Observatory, and again in April 1994 on STS-59, the first SRL mission, coordinating science operations as Payload Commander. Currently deputy chief of the Astronaut Office, Dr. Godwin will fly to the Mir space station on STS-76 in spring 1996. She holds a B.S. in mathematics and physics from Southeast Missouri State 
University, and an M.S. and Ph.D. in physics from the University of Missouri.

Peter J.K. "Jeff" Wisoff has been a mission specialist astronaut at the Johnson Space Center since 1990. Prior to joining NASA, he served on the Rice University faculty from 1986-1990 as a laser physicist. He flew on STS-57 in June 1993, where he performed a spacewalk outside Endeavour to evaluate tools and space construction techniques, and manually stow antennas on the European Retrievable Carrier Satellite. Dr. Wisoff next orbited Earth on STS-68 in October 1994, directing science operations on his shift of this round-the-clock Mission to Planet Earth. He currently represents the Astronaut Office in planning for science utilization aboard the International Space Station. He holds a B.S. in Physics from the University of Virginia, and an M.S. and Ph.D. in applied physics from Stanford University.

Cindy A. Evans is a geologist in the Earth Sciences Branch at Johnson Space Center. She joined Lockheed-Martin Engineering and Sciences Corporation in 1987; currently Dr. Evans plans space shuttle and Mir Earth observation campaigns, and trains both American and Russian astronauts for Earth studies. Her research interests include applying the resulting Earth imagery to problems in geophysics and Earth sciences. Prior to joining the Earth Sciences Branch, she taught at Colgate University for two years, and worked as a scientist for an additional two years at the Lamont-Doherty Institute. She holds a B.S. in geology from the University of Rochester, and a Ph.D. in Earth Sciences from the University of California--San Diego.

David L. Amsbury is a geologist with the Earth Sciences Branch at NASA's Johnson Space Center. He was an exploration geologist with the Shell Development Company before joining NASA in 1967. His first assignment was acting as liaison between NASA's Earth Resources Program and the geological community. For the past 29 years, Dr. Amsbury has expanded that role, coordinating imagery requirements, training crews and planning Earth observations for piloted space missions; his work has contributed to the compilation of an extensive imagery collection to address problems in the Earth sciences. Most recently, he was the Mission Scientist at JSC for the 1994 SRL missions. Dr. Amsbury is currently developing plans for Earth imaging from the International Space Station. He holds a B.S. in geology from Sul Ross College in Alpine, $T X$, and a Ph.D. in geology from the University of Texas. 